\title{
Can we ever obtain the data we would like to have?
}

Working Paper

Author(s):

Axhausen, Kay W. (D)

Publication date:

1996-10

Permanent link:

https://doi.org/10.3929/ethz-b-000450670

Rights / license:

In Copyright - Non-Commercial Use Permitted 
Can we ever obtain the data we would like to have?

Final draft

KW Axhausen

Institut für Straßenbau und Verkehrsplanung

Leopold-Franzens-Universität

Technikerstr. 13

A - 6020 Innsbruck

Tel.: $\quad+43-512-5076902$

Fax.: $\quad+43-512-5072906$

EMail: k.w.axhausen@uibk.ac.at

\section{October 1996}


Paper

Can we ever obtain the data we would like to have ?

KW Axhausen

Institut für Straßenbau und Verkehrsplanung

Leopold-Franzens-Universität

Innsbruck

\begin{abstract}
The increasing sophistication of the models used to describe travel behaviour raises the question, if the data needed to drive such models can ever be obtained on a large scale. The paper will discuss the interaction between the available and conceivable future models and our ability to collect data on human behaviour by observation and self-report in the laboratory and in the field.

The paper will have the following structure: a discussion of our current understanding of the activity stream and its structure followed by a description of the approaches used to capture the activity stream in the laboratory and in the field. A discussion of the current modelling approaches and their development directions, in particular in the area of activity scheduling, is then contrasted with the existing data limitations. The final section will try to outline future research needs in both modelling and data collection.
\end{abstract}




\section{INTRODUCTION}

Past practise in transport planning never had any doubts, that it had the data it needed for its tasks: OD data/travel diary data, screen line and other counts, supply data was assumed to be correct, complete and sufficient for the models used to give the answers which the planners had been asked to give. While one is justified to doubt the models and the data used, they probably sufficiently matched the level of sophistication of the questions asked, which concerned mostly rather crude changes to the network and other supply parameters, such as costs or timetables. It is only recently, when the frequent blockage of the application of these past solutions has led to a search for new, less crude solutions, that transport planning has started to doubt its modelling and its ability to obtain all the data required.

The new solutions are well known, if seldom implemented:

$\bullet$ (market) pricing of

-road space by link, time-of-day, day-of-week and season

-parking space by location, time-of-day, day-of-week and season

-public transport by line/location, time-of-day, day-of-week and season

-residential and office space by location and quality

-innovation in the pricing regimes

-discount instruments for public transport, such as the German Bahncard, which gives a $50 \%$ discount on all tickets for a year for a one-time payment of DM 220 (second class) and DM 440 (first class).

-loyalty schemes, such as frequent flyer cards

-season tickets for whole groups, such as the Semesterticket at German universities providing all students with a season ticket for the term for a single heavily discounted price

$\bullet$ (de)-regulation of

-time-space regimes, e.g. shopping hours, as in Germany or Austria, service times, as public houses in the UK etc.

-working hours, including options such as telework, telecommuning etc.

-service provision, e.g. regulation of public transport, car sharing or telecommunications services

-land use patterns

-information provision, as

-current measurements/estimates for traveller and network operators

- short-term/long-term forecasts for travellers and network operators

-traces for the network regulator

-access to shopping and services, e.g. travel agencies etc.

Some of the older ones remain popular, but are often impossible to fund or implement: 
-supply change

-network capacities, in particular also telecommunication capacities

-network services, i.e. lanes open, busses running, green times etc.

-residential or office space

What is not well known, is how these new measures will interact with the activity systems of the travellers, what primary long-term and secondary short-term effects these changes will have. Even the primary short term effects are difficult to assess, as most models used to evaluate them do not offer the full range of behavioural flexibility actually required to make that full assessment.

Good examples are the effects of urban congestion pricing, pricing of parking or of radio-based information systems on the overall activity patterns. The studies have generally focused on the primary effects, but have not attempted obtain a complete assessment of all effects (See for example Polak, Vythoulkas, Jones, Sheldon and Wofinden, 1993).

Even for the traditional solutions some basic questions are still without a satisfactory answer: the amount of induced demand ${ }^{1}$ or the interaction between telecommunication and the demand for physical travel come to mind (SACTRA, 1995; Claisse and Rowe, 1993).

The main problem for most existing model types is that they are trying to capture policies aiming to modulate demand in time and space in a static framework. The frameworks are static as they assume that the whole period they treat, be it an hour or a whole day, is planned and optimized in one step and that all activities are optimized with reference to that period only. If the reverse is true, i.e. that persons do not construct their behaviour in one step and that all of their activities have meaning at longer time frames, then new types of models are necessary to describe the effects of policies with confidence.

Recent developments are trying to address these challenges from a variety of directions (See Axhausen and Gärling, 1992):

-expansion of the coverage of joint models of the choice of activity pattern, timing, destinations and mode employing utility maximising principles (Ben-Akiva and Bowman, 1995, or similar work undertaken by the Hague Consulting Group and its collaborators).

- explicit scheduling models, which try to model the process of the sequencing of given activities employing a mixture of heuristic and utility maximising principles (Gärling, Brännäs, Garvill, Golledge, Gopal, Holm and Lindberg, 1989 or Ettema, Borgers and Timmermans, 1995).

-activity pattern execution models, which supplement given activity pattern with information about destination, mode and timing, again employing a mixture of heuristic and utility maximising principles (Axhausen and Herz, 1989, McNally, 1996 or much more

\footnotetext{
$1 \quad$ Understood here as the generation of completely new trips
} 
sophisticated the models AMOS (RDC, 1995) or TRANSIMS (Smith, Beckman, Anson, Nagel and Williams, 1995).

With the exception of Axhausen (1992) all of these have separate models for the generation of the travel demands and the behaviour of the network. These approaches cover to a smaller or larger extent the behavioural dimensions of interest:

- Long-term

-participation in employment

-choice of employment location

-participation in education and other long-term commitments

-choice of residential location

-vehicle ownership

-season ticket ownership

-ownership of discount instruments

-licence ownership

-ability of cycle

-medium-term

-participation in "projects" (see below)

-allocation of tasks to household members

-Short-term

-participation in out-of-home activities

-formulation of activities

-activity selection

-activity sequencing

-choice of information systems

-amount of information acquisition

-choice of activity duration

-choice of persons involved

-choice of location

-choice of mode

-route choice

The purpose of this paper is twofold: the first is to go a step backward and to scrutinize the assumptions about the activity stream which are built into the modelling approaches mentioned above; the second is to speculate about the data needs and modelling frameworks resulting from such a query and the resulting conceptualization of the activity stream. At this stage, it can only speculate given the absence of suitable empirical work - assuming it is possible - and the absence of implemented modelling frameworks. It is hoped that these speculations will foster an interest in the empirical and modelling work implied by these discussions.

The next section will discuss the activity stream and the different possibilities to conceptualize it, while the following section will discuss the data items needed to capture it and the possibility to actually 
survey them in the field. The form of suitable modelling frameworks will be sketched in final section before some concluding remarks.

\section{THE ACTIVITY STREAM}

The traditional view of transport planning is that human behaviour consists of clearly defined elements, called activities, which have a start time, duration, location and purpose. The purpose does not change for the duration, which is fixed a-priori. The number of purposes distinguished is normally limited to six to ten. The categories range currently from the general catch-all "At home" to the specific "Picking somebody up/dropping somebody off", although earlier schemes were content with an even less specific set: "home-based work", "home-based other", "non-home-based".

This paucity of description reflects the past focus of transport planning on the morning commute, i.e. a single type of trip. The activity following the trip was actually rather irrelevant to the modelling, as none of its further characteristics, in particular exact timing and duration, were used in the modelling. The method used matched the question asked (Weiner, 1988).

Time budget research has a richer description of human behaviour, as it accommodates the idea of secondary activities, i.e. things done or persons attended to in parallel with a main activity, among a small number of others. Still, time budget research has in the past not added any further dimension to its description of the activity stream beyond those used by the transport planners. It has only been recently, that further dimensions, such as "person(s) with whom the activity was undertaken" or "for whom the activity was undertaken" have been added (Ås, 1978, Szalai, 1972 or Grønmo and Harvey, 1982).

While time budget research encourages respondents to be as accurate as possible in their description of the activity undertaken, it also encourages them to think of activities as something happening in 15,30 minutes, or even longer blocks depending of the survey format used ${ }^{2}$. The accuracy desired is specified for the respondent either by examples or by coding lists. The current EUROSTAT coordinated time budget survey undertaken by the EU member states employs for example a coding list of about 120 activities, which is an order of magnitude higher than usual in transport planning. Nevertheless, the codes include rather undifferentiated categories, such as "work" or "education", which summarize a multitude of different activities.

Introspection and observation show, that the reality of our behaviour is more complex. It is rather less a series of neat packages than a stream of interwoven acts and purposes. The speed of change between

There are alternative survey designs, but the roostered time interval design is the most popular. 
acts/purposes varies from uninterrupted sleep ${ }^{3}$ to the frantic business of a secretary in a busy office or of a mother in a household with many children. This stream is aggregated naturally into higher order categories or block/activities by the respondents, as the multitude of different acts cannot be remembered, but the researcher should be aware that the importance of the acts varies and is not constant over the duration of the constructed activity (Gärling and Garvill, 1993).

It should be stressed then, that the activities we obtain from the respondent are a construct, which the respondent builds in response to the instructions of the researcher. The instructions state or imply the level of abstraction and the expected number/duration ${ }^{4}$. It would be interesting to see, if the level of abstraction, with which daily life is reported in normal story telling, is the same in different cultures or if some cultures produce markedly more or less detail ${ }^{5}$.

Transport planning and time budget research focus on "purpose" to describe the intent of the activity, but purpose is only loosely tied to the actual acts performed. One only has to think of the type of acts covered by the purpose work. Still, from a modelling perspective these different types of acts will have a major impact on the choices of the worker.

Equally, there is no clear link between an act and a purpose: preparing a meal can be paid work, pure leisure or part of home work. The description by one is not complete without the other.

There are two more aspects, which should be considered in the description of an act. One is the meaning this act or activity has for the current longer-term aims of the person. This longer-term can be rather short term in absolute terms, but it is longer then the time frame of the act/activity. It should be clear that multiple meanings of equal rank are possible, as well as multiple higher order meanings/aims. At a relatively long-term perspective meanings can be as mundane, as earning a living or as lofty as to educate oneself. At a shorter term perspective, the equivalents could be to keep a tidy house or to keep informed about the politics of the day.

The other aspect is the project, to which the act/activity belongs. A project is a set of acts/activities, which belong together to produce a specific object or to stage a specific event: writing a book, furnishing a house, financing a holiday, having a dinner party. They have a starting point and an end point, which is either the successful achievement of the aim or the final abandonment of the project. They also have a history: they are formulated, interrupted, delayed, transformed, rested, slowed down or accelerated, abandoned and picked up again.

\footnotetext{
Although even there, different elements address different purposes (dreaming, non-dreaming etc.)

4 It is known, that the number of trips provided for on a form will influence the number of trips recorded by the respondents.
}

5 See similar discussions about the way men and women deal with everyday life in their discourse. 
Projects are the concrete realisations of the aims of the person, but they can in some cases become an aim in their own right. This has happened when the person has to ask himself "Why have I done this", after a project has been concluded. It should be stressed that against a specific time frame not all acts belong to a specific project. There are then many activities, which form the background for those specific projects. They are the "overhead" for the various projects. In contrast, all acts have meaning, even if in some/many cases the aims they fulfil are very short term; e.g. watching tv to kill some leftover time.

A fourth major element, next to type, purpose and meaning, is the value or utility derived from it. The pleasure of doing something or achieving something.

To summarize the discussion so far, the individual acts of the interwoven stream should be described by:

-type (what is being done)

-purpose (for what is it done)

-meaning (why is it done)

-utility (how enjoyable is it/having done it)

-project (to which, if any, does it belong)

-participants (who else is involved)

-time (when did it start)

-duration (how long did it last)

-location (where did it happen)

-tools (what was needed to make it happen, especially money, vehicles and telecommunication devices)

Consider the example of a telephone call, which could be for work (purpose) done for a living (meaning) to set up a meeting (project) with a client (participant) using a mobile phone (tool) in the traffic jam on the motorway (location) starting at 8:45 (time) and lasting four minutes (duration). Equally it could be done for sport (purpose) to keep fit (meaning) to set up a game (project) with a squash partner (participant) using the office phone (tool, location) from 10:00 to 10:15 (time, duration).

The discussion of projects and aims highlights the fact, that the acts/activities we observe during a day belong to many different time horizons forming a complex system of temporal constraints. In addition, the existence of these projects and aims implies, that the person has always a backlog of activities, which could be undertaken to further the current projects or advance new ones. The long-term calender of activities, which have been already been identified, but not scheduled, should hardly ever be empty It also implies, that the activities observed on any one day are as a rule not random for a particular person, but reflect the needs and schedules of his/her projects. Clearly, the schedules can be interrupted by unforeseen events, such as surprise visits or sudden opportunities. These random elements have to be 
identified in a survey and not assumed, just as one cannot assume that the behaviour reflect an optimal solution constructed by the person at the start of the day.

Furthermore, if we allow for the fact, that some activities do not achieve their purpose: e.g. we could not obtain the item we wanted to buy; we did not meet the person we had arranged to meet because we were delayed by traffic; the movie became unbearingly silly instead of funny, then it is possible that the schedule outlined at the beginning of the day, will be changed dynamically: activity durations are shorter than originally planned; activities are brought forward from future days; activities are rescheduled or rearranged. The same applies for activities, for which we achieve the purpose faster than expected: the meeting comes to a resolution early; the item is found immediately; we travelled faster than we expected.

The projects, their associated activities, sequences and time horizons, are worked out at any one time in different levels of specificity by the travellers. The detail known will vary with the importance of the project, the time until it has to be finished and the completion of the other projects. Also, the detail will vary over the time horizon of the project, but not necessarily will the detail be highest for those activities planned for the near future. For examples, the dates for a holiday including the details of the flights and the trips to the airports will be known exactly, but none of the preparatory work needs to be scheduled until about a week before departure. In contrast, a lecturer might know exactly when he has to prepare the next lecture, but has no idea about the timing of the preparations for the following ones.

The calender of the institutions and of the year impose rhythms on the projects of the population. The seasons encourage and discourage certain activities. The school year and the legal holidays define opportunities for long-distance travel or local festivals. The terms of a university defines the cultural programming of a town. The time table of a sporting league tie its fans to the radio or television. The unique combinations of these various rhythms make the idea of a "normal" day or "week" moot, even an "average" day might be average for the wrong reasons.

The idea of projects and aims also highlights the importance of the commitments persons have to particular activities and by implication other persons, locations and times, as belonging to that larger frame. What we observe, can only be understood in relation to these longer time frames.

These self-imposed constraints are in addition to those socially imposed. Hägerstrand's (1970) classification of authority, coupling and capability constraints is still useful here, but should be given a dynamic dimension. In particular, the coupling and capability constraints can be modified by the individual over time $^{6}$. The coupling constraints involving other persons can be renegotiated or some times, at a cost, be ignored. We phone up to announce a delay or to rearrange a meeting. We stop visiting our parents each weekend, etc. The capability constraints are changeable over a longer time frame by training (to walk

The change of the authority constraints requires common, political action. 
faster, to cycle longer distances, but also by getting to know the environment better) or by acquiring new tools (a vehicle, a mobile phone, a new home at a different location etc.). It should be pointed out that these resources and capabilities have their own time horizons and rhythms. They take time to acquire, they take time to maintain and because of the transaction costs, they are not immediately exchanged. They also form consistent sets, which gives change a discontinuous profile (Jones and Clark, 1988). A good example is a house in the exurbs, which requires a car for every driver, in-home entertainment facilities etc., or equally the urban flat with no car parking space and no space for even a tv set. To the extent that travellers can select their ownership/membership of a set, our observations will be of selfselected samples.

The time horizons for the renewal or disposal of the various tools a household/person owns generate additional rhythms, which have to be considered in the analysis of activities. The ownership of a season ticket binds most travellers to public transport for the whole season. All discussions and preparations for possible change are likely to be concentrated in the time just before the end of the season.

In the discussion of tools and resources, one should not forget that travellers have not only means, time and money (Heidemann, 1990), but also social means, i.e. the ability to draw on the means, time and money of other persons. This allows the traveller to relax constraints by getting other people to achieve certain aims, but it in return means that at other times the traveller might be constraint to do favours for others. The degree of reciprocity involved might range from the straight tit-for-tat to the completely altruistic. It might involve straight "loaning" of time to any mixtures of means, money and time (in the form of gifts, services or loans). The length of the settling periods will vary from the relatively short term, lets say with the neighbours, to the long-term for members of the family. These exchanges will therefore not necessarily be describable by an instrumental utility maximizing framework (HargreavesHeap, 1989), which in turn means, that different logics of behaviour might structure a day.

The discussion has sketched a view of the activity stream as dominated by the constraints of the season and the available tools, money and time and divided between specific projects and a background stream of activities. The classification of a specific activity to either class will depend on the time frame of analysis. Daily work could be considered part of the background stream for a short-term analysis, while it could be part of a project to acquire a house or other item, when considered over the longer term.

In addition, while the activities reflecting basic needs, sleeping, eating, hygiene, will in general be part of the background stream, under certain circumstances they might be part of a project, for example, if the dinner involves non-household members as guests. 
We know about the rhythms of those basic physiological needs, even if they can be manipulated and suppressed to a certain extent, but we have no empirical data about the choice and rhythm of the various project people engage in.

It is useful to distinguish activity needs and activities/projects, when talking about the modelling of activity patterns. Activity needs are the normally unconscious product of the physiological and emotional needs of the person, although in planning the person can anticipate them (Dennett, 1991 or Edelman, 1994). These needs become aware, when certain thresholds are reached. A person does not have to think about hunger. The person is hungry. In contrast, activity scheduling is a conscious process by which the activity needs are translated into distinct activities. It is at this stage, that projects of different time horizons get formulated. The choice of the particular time horizon is crucial, as the scheduling of the next week or month requires different levels of detail from the scheduling of the next hour or half-day. The person has always to maintain the consistency between these different horizons, although we know from introspection and observation that sometimes certain time horizons are given precedence over other: going swimming on a fine summer day, instead of writing a paper, is a good example.

Activity scheduling will be triggered, among other situations, when the performance of the activity does not meet the expectations. While in many cases it is impossible to change the schedule immediately, there are enough times, when it can be changed. Consider for example an outing with the wrong kind of weather, a boring book or tv show. In these case, one can return early, change the book or tv show. In contrast, it is rarely possible to leave a committee meeting early or send the in-laws away.

These discussions add further items to the activity description, as well as adding further types of data. The data items concern the meaning of the activity as performed and their planning history:

-When was it first conceived?

-What was the original aim/context/meaning?

-When was it scheduled for the first time?

-When was this successful execution scheduled?

-When did the original aim/meaning/context change ?

-When could it have been performed last and still achieve its current aim/meaning ?

-Who/what was the beneficiary of the activity?

-What could have replaced it and still achieve the same aim ?

- How easy/at what cost could it have been replaced ?

- Could it have been dropped and how easily/costly?

- How important was it in comparison to the other activities performed and still planned for the day?

-To what extent were the aims of the activity achieved?

-When was this type of activity performed last ? (type could be defined at various levels of complexity)

-What was the earliest/latest time for the performance of the activity today? 
-What were the alternative venues for it?

Next to the activities performed, the further data needs are:

-the known activity needs

-the activities formulated

-the activities planned for a particular time period

described with the same items as the activities performed, but with the questions asked in the subjunctive.

The item "Aim achievement" is crucial, as it indicates the success and satisfaction with the activity. Transport planners, as a rule, have not concerned themselves with this issue, but in the context of activity scheduling it becomes essential to know, whether the activity performance was as expected, or whether the traveller had reason to extend the activity or cut it short.

To complicate matters, the achievement can be usefully divided into two components: goal achievement utility and process utility (utility of having done something versus doing it) (see Gärling, Axhausen and Brydsten, 1996; or Winston, 1982). How these two components accrue will be dependent on the type of activity, its purpose and its meaning. The goal achievement utility can accrue at the beginning of the activity, if the participation alone has value to the traveller. Consider, for example, the presence at a celebration, where the purpose is achieved when the person has congratulated the guest of honour. Equally, for the chair of a meeting the goal achievement utility accrues at the very end of the meeting, when he/she has been able to achieve all of his agenda. The process utility is normally assumed to be increasing, but there is no reason why that should be the case in the presence of a goal achievement utility: for example, being at a dentist is a thoroughly unpleasant experience only endured for the removal of the pain or the improved dental health.

\section{Data COLLECTiON}

The conceptualisation of human behaviour sketched above as activity needs of time and situation varying importance, which are than first translated into lists than schedules of planned activities and finally into actions implies a model of continuous dynamic change. The matching ideal data collection method is the multiday observation/selfreport of the plans and the executed activities.

This would require the respondent to report 25 items instead of the current 6-7 (location, time, duration, purpose, group size, vehicles used/money spent, type of location), not only for one type but for up to four types of abstractions (needs, activities formulated, schedules and executed activities), of which the first 
three could be reported at multiple times during a day or other period. In addition, not only one day with the average three out-of-home activities would be covered, but multiple days and more activities, including in-home and at-work activities, but also telecommunication usage.

It is unlikely that a sample of persons willing to accept such a task is still representative of the population. The level of literacy, introspection, conscientiousness, commitment and free time seem unlikely to be available in many cases. In addition, these respondents would have to be willing to change reported plans, i.e. not to feel bound by what is known to a stranger. Also, the respondents would have to be willing not to plan in too much detail or to omit things, i.e. not to respond with changed behaviour to the survey situation. Given the intrusiveness of the requirements, this seems unlikely in most cases.

In this sense, transport planning will never obtain all the data we need consistently from one person. It will be necessary to divide the items across different instruments. The following come to mind:

-multiday activity diary expanded with some additional items

-multiday activity schedule survey

- survey of weekly/monthly activity plans/schedules

-diary of activity schedule and activities

-SP survey of scheduling

-Gaming simulation of rescheduling

although other combinations are possible. This is a first suggestion and needs to be refined and revised after testing.

\section{Multiday activity diary expanded with some additional items}

The current one-day diaries of travel behaviour give us no idea of how the activities reported fit into the on-going projects of the respondents. Most of the diaries do not give an idea of the type of in-home, atwork or telecommunication activities, which might be converted into out-of-home activities, although some recent American surveys have made progress with respect to in-home activities. Equally, some recent German work has shown, that it is possible to obtain information about telephone calls (incoming and outgoing) from a diary instrument.

The task of this survey would be to span a substantial number of consecutive days, ideally weeks such as the 1973 Uppsala survey (Hanson and Huff, 1982), and to cover the in-home, out-of-home and at-work activities (private calls, lunch or other breaks, banking or shopping, if such facilities are available at the work place). Ideally, the use of telecommunication tools should also be covered. Each activity should be described with:

-Location (Start location, if a movement)

-Start time

-Duration 
-Tools used (vehicles, telecommunication)

-Party (size and composition)

-Money spent

-Purpose

-Achievement of aims

-When first planned

-Associated project, if any

Given the workload implied, the coding of the items should be relatively crude. Also, one could consider the use of a computer-based instrument, which the respondent could carry with him or her.

This survey would give transport planning for the first time a partial understanding of the longer term structures of everyday life. The impoverished understanding based on single days could be overcome.

The question item "Achievement" requires special care, as achievement has purpose and meaning specific dimensions, while also being divided in goal achievement and process elements. The possibilities of CATI/CAPI technologies allow appropriate context sensitive questioning, but experimentation is required.

\section{Multiday activity schedule survey}

Matching the first survey, this survey would focus on the plans for the day, recorded either the evening before or in the morning. The day as a unit for the plans and as recording interval is arbitrary, but natural given the many rhythms, which work on a daily basis. The description of the activities would be identical to the one above, but the respondents would be encouraged to use the "Don't know" category in preference to omitting planed activities for embarrassment.

Clearly, it would be best to have the same person perform both surveys, but given the extraordinary work load this would imply and the various possible biases, a separation seems required for long duration surveys.

The comparison of planned patterns and realized patterns and the degree to which plans are detailed would give us insights into the degree to which the transport/activity system fulfils the desires of the populations and to what extent the travellers can change or adapt their behaviour.

\section{Survey of weekly/monthly activity plans/schedules}

Extending the scope of the last survey this survey should obtain an idea of the overall structure of the various projects, in which a person is engaged at any one time. This survey should also probe for the 
various dimensions of meaning (temporal, personal, household oriented etc.). The description of the activities should be as in the fist two, but solicit ranges of values and make it clear to the respondent that empty space in the calendar is normal and does not need to be filled at any price.

The results would give us an idea about the amount of advance planning and about the timing of the detailing of the projects/activities. It would also the reveal the number of projects and their relative sizes and importance in terms of time, money and number of persons involved.

\section{Diary of activity schedule and activities}

For a one day diary it is conceivable that respondents would be able to deliver both planned and executed activities. Obviously, the main objective is to see how the plans are transformed and changed by failures, delays or unexpected opportunities.

It is very hard to say a priori what the best format for such a survey would be. While mail out/mail-back surveys might be possible, a mixture of a telephone interview and a written instrument might be best with the interview establishing the plans the evening before and the written instrument recording the actual performance. The description of the activities would be the same as in surveys discussed above.

\section{SP survey of scheduling}

The success of Ettema's MAGIC (Ettema, Borgers and Timmermans, 1993) survey has suggested, that it is possible to obtain information about activity scheduling and schedules from stated-preference type surveys. Ettema used a list of activity types to prompt the respondents to formulate activities and to schedule them subsequently. His focus was both on scheduling as a process, as well as the quality of the resulting schedule.

Two types of work should be performed. The first type should focus as Ettema's has on schedule construction from scratch, i.e. from a list of activities drawn from the long-term calender including background activities, while the second type should focus on rescheduling existing schedules under the impact of unexpected changes (delays, faster achievement of goals etc.).

The context of the SP-interview should also be used to record a completed day with all the items discussed above. Both as a database in its own right, as well as an exercise to alert the respondent to all the various elements to be considered.

The observations from the SP would allow the modelling of the individual scheduling process and of the schedule quality aimed for while the traveller is constraint for the day/period.

\section{Gaming simulation of rescheduling}


The SP-work described above is restrictive in dealing with only one person at a time and in focusing the attention of the respondent very strongly on "plan achievement". In the tradition of HATS (Jones, Dix, Clarke and Heggie, 1983) or CUPIC (Lee-Gosselin, 1996), these gaming simulation exercise should stress the collective element of the decision making process and the trading of responsibilities, resources and tasks in the household group/social network. In this setting, it would be useful to make a multiple day period the subject of the experiment, as exchanges between household members are less likely during the daily time frame due to the difficulty of communication and coordination. The first phase of the experiment should construct a week, while the second phase should introduce an element of stress (a member of the family visiting, a sick person, a broken car, a public transport strike, extra work at the place of employment etc.). The participants should be encouraged to think about as wide ranging changes as appropriate, in particular about longer-term resource commitments and changes.

The analysis of the gaming simulation would give insights into the trading of tasks and responsibilities in addition to the opportunity to model the scheduling process and its outcome.

\section{MODELLING DIRECTIONS}

The description of the data collection efforts above implies a disaggregate modelling approach to the description of the questions raised above. Before describing two conceivable disaggregate modelling frameworks, one might want to consider, that given the difficulties with the data, which will always imply a pieced together data base, whether one should abandon disaggregate approaches and explore the possibilities of rather more restricted, but consistent aggregate approaches to the individual questions.

The two frameworks to be discussed are the extremes along a continuum of possibilities. These extremes could be labelled an evolutionary approach and an equilibrium approach.

The evolutionary approach would describe the persons individually as the agents of a simulation and how they change under the impact of the various policies implemented at different times during the simulation run. Each day simulated would imply a specific date in the development of the system with all the specific characteristics of a specific day (season, weather, events, social time-space regime for the days (school holidays etc.), random incidents). The simulated persons would learn, i.e. change their memories of the system performance, and they would age and change with their household. The network simulation/simulation of the behaviour on the network is part of the demand simulation. The agents respond directly to the network performance by rescheduling the day, week etc. 
The scheduling model would, most likely, be a satisfycing heuristic and would explicitly address the issue of project generation and abandonment. The background activities would be generated through a system of competing hazard-type functions indicating the increase in urgency over time. Past solutions would be reused, if possible. The agents make their choices on the basis of expected performance or information provided and adapt their behaviour on the next day or at the next opportunity.

The results of the simulation would be less the mean performance of the system, but the variability of the system and the paths the system takes during its evolution. No "specific" state, such as an equilibrium or only steady state, is achieved or aimed for. Multiple runs of the system would be required.

It is obvious, that such an evolutionary system could be made to produce a steady state or even equilibrium solution by either removing elements of variability or by respecifying the objectives of the scheduling model.

A steady state solution will be required as the initial solution and used to validate the model against observed conditions in the urban area modelled. It is likely that different initial solutions reproduce the aggregate criteria used for validation.

The equilibrium solution at the other extreme will generate a consistent solution with prespecified characteristics, i.e. those of a dynamic Wardrop equilibrium suitably extended to address the choice of activity sequence, timing and duration. Assignment or simulation of the network will be separated from the adjustment/calculations of the demand structures, like in the current TRANSIMS model (Smith $e t$ al., 1995). The rules for the calculation/adjustment of the demand structures can be without relation to human decision processes, as long as they are able to produce a valid solution. Memory processes will also be ignored. The "days" of the iterations have no meaning beyond tracing the process of convergence.

Both approaches face the challenge of showing that their status-quo solutions are consistent with the behaviour data and aggregate network behaviour. Given their claim to model scheduling, it will not be enough to reproduce aggregate statistics about link flow or speeds, or even activity durations and the distributions of the activity chain. For both purposes the developers will have to develop methods to compare the joint sequence, timing and duration distributions. To the best of my knowledge, there has been no substantial work in this area since the work of Recker and McNally (1985), Pas (1984) and Schmiedel (1984) in the early Eighties.

Obviously, both approaches will be extremely computationally intensive and it is not clear, when the computing times will be brought down to a practicable level. The consequence of these demands is, that the models will have to be used in a focused manner and in combination with less comprehensive 
models. In analogy to the approach of SATURN (Van Vuren and Vliet, 1992), for example, which models a core of the network in great detail, while abstracting the surrounding network, one could consider running the model for a particular area or social group with all detail, while modelling the remaining area/social groups more crudely.

The inclusion of "memory" raises enormous questions, as our knowledge of the dynamics of the mental mapping of the performance characteristics of networks and of activity opportunities is virtually non existing. Initial experiments (Mahmassani or Axhausen and their collaborators) show complex learning mechanisms already for small networks. Work for real-life situations is unknown to the author. This is an area, in which collaboration with and cognitive psychologists is urgently required.

\section{CONCLUSIONS AND FUTURE DIRECTIONS}

The challenges of the current policy discussion require that transport planning models accommodate the generation, definition and scheduling of activities in a household context. Otherwise, the models are wide open to accusations of incompleteness.

This paper has sketched a conceptualisation of the human activity stream as a series of projects, which at different time frames either retain their distinct project character or become "overhead", every day life. Modelling can progress, either by trying to trace the dynamics of the projects, spanning in many case multiple days or periods, or by developing tools which generate schedules consistent with real behaviour for any one day essentially ignoring the dynamics of the projects (See also Axhausen, 1991).

The data needs for the first type of model are prodigious and it will be nearly impossible to establish a population sample, which returns all the required information from the same persons. The information needs will have to be split among different instruments. The majority of these instruments are new and will require testing and piloting before they can be used on a large scale.

Three topics require special attention: methods to establish the consistency of generated activity schedules with observed activity schedules; models of network learning and attributation and finally algorithms to extract decision heuristics from SP-experiments or gaming simulations. 


\section{ACKNOWLedGements}

This paper expands ideas first presented as "The data needs of activity scheduling models" (Axhausen, 1995). The author is grateful for the comments received during the conference "Theoretical Foundations of Travel Choice Modelling" (Stockholm, August 1996) and in particular those of Tommy Gärling.

\section{REFERENCES}

Ås, D. (1978) Studies of time-use: problems and prospects, Acta Sociologica, 21 (1) 125-141.

Axhausen, K.W. (1990) A simultaneous simulation of activity chains and traffic flow, in P.M. Jones "Developments in Dynamic and Activity-based Approaches to Travel Analysis", 206-228, Avebury, Aldershot.

Axhausen, K.W. (1991) The role of computer-generated role-playing in travel behaviour analysis, paper presented at the 69th Annual Meeting of Transportation Research Board, Washington, DC..

Axhausen, K.W. (1996) The data needs of activity scheduling models", presentation of the International Conference "Activity based approaches: Activity scheduling and the analysis of activity patterns", Eindhoven, May 1995.

Axhausen, K.W. and R. Herz (1989) Simulating activity chains: a German approach, Journal of Transportation Engineering, 115 (3) 316-325.

Axhausen, K.W. and T. Gärling (1992) Activity based approaches to travel analysis: Conceptual frameworks, models and research problems, Transport Reviews, 12 (4) 323-341.

Ben-Akiva, M.E. and J.L. Bowman (1995) Activity-based disaggregate travel demand modelling system with daily activity schedules, paper presented at the International Conference "Activity based approaches: Activity scheduling and the analysis of activity patterns", Eindhoven, May 1995.

Claisse G. and F. Rowe (1993) Domestic telephone habits and daily mobility, Transportation Research, 27A (4) 277-290.

Dennett, D.C. (1991) Consciousness explained, Allen Lane - The Penguin Press, London.

Edelman, G.S. (1994) Bright light, brilliant fire: on the matter of the mind, Basic Books, New York.

Ettema, D., A. Borgers and H. Timmermans (1993) Using interactive computer experiments for investigating activity scheduling behaviour, Proceedings 21st PTRC Summer Annual Meeting Seminar P, 267-282, London.

Ettema, D. A. Borgers and H. Timmermans (1995) SMASH (Simulation model of activity scheduling heuristics): empirical test and simulation issues, paper presented at the International Conference "Activity based approaches: Activity scheduling and the analysis of activity patterns", Eindhoven, May 1995.

Gärling, T., K.W. Axhausen and M. Brydsten (1996) Travel choice and the Goal/Process Utility Distinction, Applied Cognitive Psychology, 10 (1) 65-74.

Gärling, T., K. Brännäs, J. Garvill, R.G. Golledge, S. Gopal, E. Holm and E. Lindberg (1989) Household activity scheduling, Paper presented at the Fifth World Conference on Transport Research, Yokohama.

Gärling, T. and J. Garvill (1993) Psychological explanations of participation in everyday activities, in T. Gärling and R.G. Golledge "Behaviour and Environment", 270-297, North-Holland, Amsterdam.

Grønmo, S. and A.S. Harvey (1982) Time-diaries and trip-diaries: a comparison, paper presented at the 10th World Congress of Sociology, Mexico City. 
Hägerstrand, T. (1970) What about people in Regional Science?, Papers of the Regional Science Association, 24, 7-21.

Hanson, S. and J.O. Huff (1982) Assessing day-to-day variability in complex travel patterns, Transportation Research Record, 891, 18-24.

Hargreaves-Heap, S. (1989) Rationality in Economics, Blackwell, Oxford.

Heidemann, C. (1990) Regional planning methodology, Discussion Paper, 16, Institut für Regionalwissenschaft, Universität (TH) Karlsruhe, Karlsruhe.

Jones, P.M. and M.I. Clarke (1988) The significance and measurement of variability in travel behaviour: a discussion paper, Transportation, 15 (2) 65-87.

Jones, P.M., M.C. Dix, M.I. Clarke and I.G. Heggie (1983) Understanding Travel Behaviour, Gower, Aldershot.

Lee-Gosselin, M.E.H. (1996) Scope and potential of interactive stated response data collection methods, Transportation Research Board Conference Proceedings, 10, 115-133.

McNally, M. (1996) An activity-based microsimulation model for travel demand forecasting, in H. Timermans "Activity-based approach to transportation modelling", Elsevier, Amsterdam.

Pas, E. (1984) The effect of se, lected socio-demographic characteristics on daily travel activity behaviour, Environment and Planning A, 16, 571-581.

Polak, J.W., P. Vythoulkas, P.M. Jones, R. Sheldon and D. Wofinden (1993) Travellers' choice of time of travel under road pricing, presentation at the 21st PTRC Summer Annual Meeting, Manchester, September 1993.

RDC (1995) Activity-based modelling system for travel demand forecasting, report to the Federal Highway Adminstration, DOT-T-96-2, San Francisco.

Schmiedel, R. (1984) Bestimmung verhaltensähnlicher Personenkreise für die Verkehrsplanung, PhD dissertation, Institut für Städtebau und Landesplanung, Universität Karlsruhe, Karlsruhe.

Standing Advisory Committee on Trunk Roads (1995) Trunk Roads and the Generation of Traffic, HMSO, London.

Recker, W.W. and M.G. McNally (1985) Travel/activity analysis: pattern recognition, classification and interpretation, Transportation Research, 19A (4) 279-296.

Smith, L., R. Beckman, D. Anson, K. Nagel and M.E. Williams (1995) TRANSIMS: Transportation analysis and simulation system, Proceedings of the 5th National Conference on Transportation Planning Methods Application, 2, Transportation Research Board, Washington, D.C.

Szalai. A. (ed.) (1972) The Use of Time, Mouton, The Hague.

Van Vuren, T. and D. van Vliet (1992) Route Choice and Signal Control, Ashgate, Brookfield.

Weiner, E. (1988) Urban Transportation Planning in the United States: An Historical Overview, Report DOT-T-88-26, US Department of Transportation, Washington, D.C..

Winston, G.C. (1992) The timing of economic activities, Cambridge University Press, Cambridge. 